\title{
Effect of the Self-Efficacy on the Perceived Ethicality of Fear Appeals in Anti-Tobacco Advertising
}

\author{
Ines Saadellaoui ${ }^{1}$ and Jamel-Eddine Gharbi ${ }^{2}$ \\ ${ }^{1}$ School of Business-Manouba, Tunisia \\ ${ }^{2}$ Laboratory League, Fsjegj, University Jendouba, Tunisia
}

\begin{abstract}
The Literature agrees that fear appeals are effective to attract attention and create motivation to quit smoking. However, theses threatening messages can easily raise ethical issues. This article outlines some ethical issues about the use of fear appeals. Also, it tries to understand the effect of perceived self-efficacy of smokers on the ethical judgment of scary advertising. The experimental study that we have conducted reveals that fear appeals are perceived ethical if smokers feel able to implement the recommendation of the message sender. Both the theoretical contributions managerial implications of such a result will be discussed in this paper.
\end{abstract}

Keywords: Perception of self-efficacy, ethical judgment, intention to quit smoking.

\section{Introduction}

The fear appeals are ubiquitous. Preachers, politicians, parents, communicators have used this method of persuasion to convince people to change their attitudes and / or behaviors (Rogers, 1983; Witte and Allen, 2000). The idea to create this negative emotion appears to be effective in social marketing (Bryant and Zillman in Girandola, 2000, Hunt \& Shehryar, 2002). Communications arousing an emotion of fear are particularly effective to attract attention, create awareness of the dangers of smoking and motivation to quit smoking (Gallopel, 2006). Empirically, it has been shown that subjects remember more ads that portray fear than those relying on positive emotions (Hyman and Tansey, 1990; Thorson and Friestad, 1985). Yet some believe that fear appeals are unethical because they can "expose a person against his will to seriously harmful or offensive pictures" (Hyman and Tansey, 1990). The fear appeals are unethical because they offend or shock the individuals. The fact of chocking individuals may reflect a lack of respect towards them.

In fact, previous research has shown that the use of fear may evoke negative reactions from consumers (Duke et al, 1993; LaTour and Zahra, 1989). However, studies like those of Tanner, Day and Crask (1989); Tanner, Hunt and Eppright (1991), La Tour and Rotfeld (1997); Andersen, (2000); Girandola, (2000) and Williams ( 2012) emphasize that the perception of self-efficacy is an important antecedent at individual's response to an advertisement. According to Gallopel (2006), neglecting the role of self-efficacy "can be catastrophic because a scare message can produce the opposite effect to that expected if an individual does not feel able to adopt the recommendation of the sender».

This study aims at explaining the effect of self-efficacy on the perceived ethics of advertising and intention to quit. These objectives justify the following order: we

Copyright (C) 2012 Ines Saadellaoui and Jamel-Eddine Gharbi. This is an open access article distributed under the Creative Commons Attribution License unported 3.0, which permits unrestricted use, distribution, and reproduction in any medium, provided that original work is properly cited. Contact author: Ines Saadellaoui E-mail: ines.saadellaoui@gmail.com 
first start by a theoretical investigation of the concept of self-efficacy, ethical judgment and behavioral intention. Then, we will present the assumptions and methodology. Finally, the main findings will be detailed.

\section{Conceptual Framework}

\section{Perceived Self-Efficacy}

The perception of self-efficacy refers to beliefs of the individual when it comes to his abilities to execute actions necessary to achieve desired goals (Garlin and McGuiggan, 2002, Bandura, 1994, 2003). It affects individual motivation, thoughts, emotions, behaviors, and has an impact upon the intended action (Bandura, 2003). The perception of self-efficacy is developed mainly through four main sources: the active control experiments, the vicarious experience, verbal persuasion and physiological and emotional states at that time (Bandura, 2003; Dao, 2004).

Direct individual experiences are the most important source of self-efficacy. They include the successes and failures experienced during the execution of previous activities. The strength of selfefficacy depends on the relative success or failure in a specific field of activity. (Bandura, 2003; Dao, 2004). Indirect experiments include learning by observation and by comparison with others. Seeing similar people through the testimonies of ex-smokers or admired as opinion leaders who succeed in getting rid of unhealthy behavior increases the perception of self-efficacy (Bandura, 2003; Dao, 2004). Additionally, verbal persuasion allows the consolidation of beliefs about personal efficiency. It concerns the views of the entourage on individual aptitude in a specific activity or in similar situational typology. Finally, the physical and emotional state has an impact on the assessment of personal abilities. We can refer here to the areas requiring physical effort (Bandura, 2003; Dao, 2004).

The concept of self-efficacy on the use of fear appeals was first dealt with Rogers (1983). The theory of protection motivation (Rogers, 1975, 1983) tries to evaluate in a logical prerequisite for effective action of a threatening message (Witte and Allen, 2000). It focuses on cognitive mediators of the relationship between fear and attitude change toward the negative behavior (Witte and Allen, 2000). The original and revised theory identifies the components of fear appeals and Cognitive mediators that lead to acceptance of the message (Rogers, 1975). The motivation for protection depends on a multiplicative combination of the three cognitive processes: the assessment of the severity of the threat, the probability of occurrence of danger and the effectiveness of the recommendation. This is a variable that triggers the change in attitude toward the harmful behavior (Rogers, 1975).

Maddux and Rogers in Girandola (2000) "do not provide empirical support for this model will lead and Rogers (1983) to abandon its multiplicative principle." A new version of what incorporates the concept of self-efficacy as a fourth cognitive variable as a mediator for the protection motivation (Girandola, 2000; Witte \& Allen, 2000; Rogers, 1983). The model of protection motivation explains when and why fear appeals are effective (Witte \& Allen, 2000). The acceptance of a message depends, at once on the perception of a severe and a personally relevant threat as well as a high level efficacy (Rogers, 1983). This theoretical approach provides four interactions between the dimensions of the threat and those of efficiency (severity* susceptibility * efficacy* self-efficacy).

\section{The Ethical Judgment of Advertising}

To create an ethical threatening advertisement, an understanding of ethics in general is necessary. In this context, Snipes, Latour, and Bliss (1999) noted that "ethics in general is investigating whether the conduct of an individual, group, or a trader is considered good or bad. It is determined by the values of an individual. «Ethical action is to act for the welfare of others" (Holbrook, 1994). According to Snipes, Latour and Bliss (1999), ethical judgment is "the degree to which an individual believes that a specific behavior is morally acceptable." The literature 
review reveals the existence of four common ethical issues: deontological ethics, teleology, relativism and the theory of justice. The deontologists attach great importance to the notion of duty. They focus on acts and intentions (Reindenbach and Robin, 1990, Duke et al, 1993, Snipes, Latour, and Bliss, 1999). Teleology determines the moral value of action or behavior by its consequences. Its ultimate goal is to achieve happiness of many people by adopting the most effective ways to achieve its though they are morally uncertain (Metayer, 1997). It should be noted that the currents contain two teleological theories: ethical egoism if the moral evaluation of the act done according to its consequences on the individual, and the utilitarianism which induces the evaluation in the relationship to the whole society (Reidenbach and Robin, 1988). Relativism means that ethical beliefs are dependent on culture and civilization. Finally, the theory of justice favors freedom and equality of all individuals (Metayer, 1997). It should be noted that consumers do not refer to these ethical approaches when they are exposed to advertising messages (Arthur and Quester, 2003). Reidenbach and Robin (1988) estimate that individuals are not using ethical theories to evaluate specific marketing activities. Researchers should consider these philosophies as mutually exclusive. Individuals use a variety of principles derived from these approaches in evaluating ethics.

Reidenbach and Robin (1990) suggest that this concept has three dimensions which are the moral equity, relativism and contractualism. The moral dimension of equity is composite. It is associated with moral philosophies of justice, the ethical approach and the relativistic approach. The second dimension focuses on the instructions, and requirements of cultural and social system. The third dimension depend on the notions of obligation, contracts, duties and rules. Researchers say that the dimensions of moral equity and relativism are more suitable than the dimension of contractualism in studies of advertising (La Tour and Henthorne, 1994; Snipes, Latour, and Bliss, 1999; Arthur and
Quester, 2004). Therefore, the last dimension will be excluded in this study. Despite the abundant use of fear appeals in advertising, little attention was given to the ethical judgement of these methods (Duke et al., 1995). Although most advertisers agree that generally the fear appeals increase the effectiveness of advertisements, previous studies show that the use of this negative emotion can cause either a positive or negative reaction from consumers (Latour and Pitts, 1989; Rotfeld, 1989). Because of the risks assumed, advertisers should be fully aware of the reactions of their target audience when it comes to the use of these potentially controversial advertising stimuli. The fear appeal can easily raise ethical issues. Hastings, Stead, and Webb (2004) suggest that fear appeals can have many negative effects. Shocking advertising can be used to manipulate human behavior, or reach and annoy the public. It deliberately promotes anxiety. It can also:

- Exploit vulnerable individuals such as the young, the sick or the ingrown and cause inappropriate reactions such as rejection and denigration.

- Evoke fear, death or anxiety.

- Encourage fatalism.

- Trigger an unwanted behavior.

- Generate vulnerability which creates an inequality that violates the principle of justice.

Finally, the fear appeal tends to violate privacy.

\section{The Behavioral Intention}

The behavioral intention is an intermediate conative component between attitude and behavior (Fishbein \& Ajzen, 1975). It represents the desire, the determination or the willingness to perform a behavior. It positively affects the probability of emitting an actual behavior.

The literature highlights the existence of two theoretical approaches explaining the 
behavioral intention which are the theory of reasoned action and the theory of planned behavior. The theory of reasoned action was developed by Fishbein and Ajzen (1975). It aims at predicting the intention from attitude and subjective norms (Fishbein and Ajzen, 1975). On the contrary, the theory of planned behavior incorporates a third explanatory variable which is the perceived control (Ajzen, 1985). The theory of reasoned action assumes that for an individual to join a behavior depends on his own attitude towards the performance of the act and subjective norm. An attitude refers to the set of beliefs about the consequences of the realization of the behavior and evaluations of those consequences. However, subjective norms refer to the set of normative beliefs and motivation of the individual to comply with the norms (Fishbein and Ajzen, 1975; Fishbein, 1980). This theory has several limitations related to behavior over which individuals have only a partial control (Ajzen, 1991). In addition, Warshaw (1980) emphasizes the absence of unanimity on the predictive power of the model and the validity of the construct.

With the addition of perceived control on behavior, the theory of planned behavior provides enrichment to the theory of reasoned action. This concept corresponds to the individual beliefs as to the ease or difficulty of performing a behavior. It takes into account the skills available to the individual, his own abilities, opportunities and resources needed to achieve a given behavior.

\section{Research Hypotheses}

\section{Arguments for the Hypothesis Concerning the Effect of Ethical Judgment of Scaring Advertising on Behavioral Intention}

Advertisers should be fully aware of the reactions (positive and negative) of their target with the use of potentially controversial stimuli. Treise et al (1994) pointed out: "consumer opinion whether the practice is immoral advertising can lead to a number of adverse outcomes, ranging from consumer indifference toward the advertised product to more serious actions such as boycotts or requests of government regulation».

In social marketing, threatening advertising reflects a lack of social responsibility of advertisers (Latour and Zahra, 1989. Treise et al., 1994). It has the potential to undermine the credibility of advertisers and create unnecessary anxiety in the viewer (Hyman and Tansey, 1990; Treise et al, 1994). It has a negative effect on the moral and physical health of individuals. This is why, they latter question the ethicality of threatening communications even though the intentions of the advertiser are good. They therefore call into question "the legitimacy of the process advertising" (Hastings, Stead, and Webb, 2004).

Treise et al (1994) add that the shocking and indecent use of fear affects the credibility of advertisers and creates anxiety and mistrust among people. Trefois (2003) reports that some health professionals stress the fact of acting on a person to adopt the desired behavior by the advertiser, is a form of "manipulation" and implementation of the adage "the end justifies the means ". This is incompatible with the objective of public health which represents a moral standard associated with the pursuit of happiness. Simpson et al (1998) report that the perception of nonethicality of advertising affects negatively the attitude towards advertising, the brand, and the purchase intent. Mostafa (2011) points out that the Egyptians have a negative attitude toward advertising posing ethical issues. The non - legitimacy of the advertisement weakens its ability to persuade: If the viewer perceives that the commercial is ethical, he will accept the advertising argument and adopt the recommendation conveyed by the advertiser. As a result: 
H1: The ethical judgment of advertising has a positive impact on behavioral intention.

\section{Arguments for the Hypothesis Concerning the Effect of Self-Efficacy on Behavioral Intention and the Perception of Advertising Ethics}

Researchers are unanimous in granting a predominant effect of perceived selfefficacy on persuasion and behavioral intention. They announce that it is vital to face the threat (Keller and Block, 1997; Hale and Dillard, 1995; Witte, 1992; Girandola, 2004; Gallopel, 2006; digger et al., 2007). Several studies have concluded that self-efficacy is important to adopt the recommendation conveyed by the advertiser (Evans et al, 1970; Leventhal, Watts, and Pagano, 1967; Sutton and Eiser, 1984). It could therefore be postulated that the perceived self-efficacy affects how the ethicality of the ad is seen, because if the target feels that the response is feasible, the threat may be perceived, as human. A low self-efficacy can negatively affect the ethicality of the ad.

Self-efficacy may therefore affect the meaning of ethical perception of advertising stimuli (Snipes, Latour, and Bliss, 1999; Tower and Shaker, 1989, Hastings, Stead, and Webb, 2004). These studies demonstrate that it positively affects the ethical judgment of advertising. If an individual feels the feasibility of the recommendation described by the advertiser in response to the threat, he accepts it and sees it as correct. In other words, a high self-efficacy makes the use of fear more acceptable in social persuasion. Hence.

H2: Perceived self-efficacy positively affects the perception of ethical advertising.

H3: Perceived self-efficacy has a positive correlation with behavioral intention.

\section{Methodology}

In this research, participants are exposed to two TV spots. The first one is highly frightening, the second is slightly scary. First, we downloaded from the internet fifteen spots tobacco. Then, marketing experts chose the most threatening advertising stimulus. Finally, this spot is subjected to adjustments to be slightly scary. The choice of the spot was based on certain criteria. We had to find an advertisement which easily manipulated since our goal is to transform a scary advertisement into a less threatening one initially sparking a minor threat. It should be noted that we opted for a nonprobability sampling method that is for convenience. The sample consists of adults with a majority of students.

\section{Choice of Scales}

Table 1 shows scales of measurement:

Table 1: Presentation of Scales' Measurement

\begin{tabular}{|l|l|}
\hline \multicolumn{1}{|c|}{ Concepts } & \multicolumn{1}{|c|}{ Source } \\
\hline The perception of personal efficacy & Etter et al (2000) \\
\hline The behavioural intention & $\begin{array}{l}\text { Pierce et al. in Pechmann et al } \\
(2003)\end{array}$ \\
\hline Ethical judgement & Reidenbach and Robin (1990) \\
\hline
\end{tabular}

\section{The Experimental Procedure}

Before broadcasting the ad, smokers respond to the questions relating to the perceived self-efficacy. After airing the ad, participants were asked to fill a questionnaire which assesses their intention to stop smoking on the one hand 
and ethical judgment of advertising on the other hand. This procedure was repeated for the second spot (the less scary spot).

\section{Results}

\section{Sample Description}

We interviewed 430 respondents. The questionnaire was administered at the Higher Institute of Applied Humanities of El Kef and the Faculty of Economics and Management, Jendouba- Tunisia. It identified the opinions of students, teachers and employees. We used SPSS 17. Men predominated (75\%) among participants. Most respondents were young, aged 20 to 29 years (65.3\%).

\section{Study of Scales}

\section{- Analysis of the Dimensionality and Reliability of Self-Efficacy}

The KMO is equal to 0.934. As for the Bartlett test of sphericity, the X2 has a high value and low significance. The principal component analysis reveals one factor that has an eigen value greater than 1 . We eliminated one item "glass" because it has a quality representation less than 0.5 . Cronbach's alpha is equal to 0.942 .

\section{- Analysis of the Dimensionality and Reliability of the Scale of Ethical Judgment}

The principal component analysis revealed a KMO of 0.875 and a great test of sphericity significant Bartlett. The principal component analysis reveals one factor that has an eigenvalue greater than 1 . Cronbach's alpha is equal to 0.885 .

\section{- Analysis of the Dimensionality and Reliability of the Scale of the Intention to Quit Smoking}

The principal component analysis indicates a KMO of 0.776 and a Bartlett test of sphericity significant. Cronbach's alpha is 0.776 .

\section{Hypothesis Testing}

H1: The ethical judgment positively affects the intention to quit smoking

Regression analysis shows that the ethical judgment significantly and negatively influences persuasion. Indeed, ethical judgment explains $14.7 \%$ of the variance in intention to stop smoking (R-square = $0,147)$. The overall regression model is significant because it shows a value of Fisher test equal to 74,004 with a probability equal to 0.000 . The regression equation is written as follows:

Intention to quit $=0384$ (ethical judgment)

$$
(t=8,603, p=0.000) \text {. }
$$

H2: Perceived self-efficacy positively affects the perception of ethical advertising.

Regression analysis shows that the perceived self-efficacy significantly influences ethical judgment. Indeed, the perception of self-efficacy explains $3.4 \%$ of the variance in ethical judgment (R-square $=0,147)$. The overall regression model is significant because it shows a value of Fisher test equal to 17,162 with a probability equal to 0.000 .

The regression equation is written as follows:

Ethical judgment $=0.185$ (self-efficacy)

$$
(\mathrm{t}=4,892, \mathrm{p}=0.000)
$$

The hypothesis H2 is confirmed.

H3: Perceived self-efficacy positively affects behavioral intention.

Regression analysis shows that the perceived self-efficacy significantly and positively influences behavioral intention. Indeed, the perception of self-efficacy explains $2.1 \%$ of the variance in behavioral intention (R-squared $=0.021$ ). The overall regression model is significant because it shows a value of Fisher test equal to 9.069 with a probability equal to 0.003 . The regression equation is written as follows: 
$=0144$ for (self-efficacy)

$(\mathrm{t}=3,011, \mathrm{p}=0.003)$

The hypothesis H3 is accepted.

\section{Discussion, Limitations, and Future Avenues of Research}

The fear appeals are controversial because they can cause negative reactions from consumers. This research provides further affirmation that self-efficacy positively affects the perception of the ethical nature of an ad. This study also shows that selfefficacy can have a significant positive effect on the intention to stop smoking. Smokers are victims of their addiction. Knowledge of the dangers of smoking does not in itself change the behavior. There should be a real support to increase the chances to get rid of this true addiction.

Additionally, it is important to infer that adults, more than young people, have a higher intention to stop smoking and display a high level of awareness of the risk they take. However, they have a low confidence in their personal abilities. This low capacity is related to physical dependence and the absence of a favorable "environment: " universities, parties, cafes, exams, disappointments" (Gallopel \& Petr, 2000). The smoking habit is "a force sometimes stronger than the willingness of the intention to stop smoking" (Kapferer, 1990). That is why, it is essential to help them get rid of this habit.

To increase the perceived self-efficacy of dependent smokers, the advertisers should develop a campaign adapted to the needs of the target by providing a pharmacological and psychological assistance. For this, it is necessary to increase the number of units staffed with competent personnel and to evaluate regularly. The cost of nicotine replacement therapy is currently very high. It is important to improve accessibility to medical care by providing reimbursement for insured (Kasper et al, 2005) and free medication for the uninsured.

In addition, ethical judgment has an important effect on the intention to stop smoking. This result is in line with those of Simpson (1992). As such, unethical ads may have a very negative impact in the short and long term (Hyman and Tansey, 1990; Thompson, Barnett and Pearce, 2009; Eckart, 2011; Palmer-Mehta, 2009). In addition, the perception of ethical advertising is dependent on self-efficacy. In the case of threatening communication, the use of fear can be seen as ethical when the consumer feels able to eliminate the threat conveyed by the advertising stimulus.

In general, individuals differ in their attitudes towards advertising and in their assessment of the ethicality of the ad. The challenge is to design a persuasive communication while creating perceptions or attitudes that are positive or ethical; for example, avoiding dramatic advertisements which exploit the vulnerability of smokers and drive unnecessary demand. These processes involve improper handling techniques (LaTour, Snipes, and Bliss, 1996). This balance of persuasion and ethics is important when individuals who do not like an ad may have a negative attitude toward the product itself (Aaker and Stayman, 1990).

The self-efficacy is important to adopt the recommendation conveyed by the advertiser. It also affects the perception about the morality of advertising. It can be inferred that increasing confidence in the consumer's ability to cope with a threatening situation is a very logical strategy to be adopted by advertisers to improve the ethicality of using fear.

This research has certain limitations: the experiment was performed under conditions of exposure which do not correspond to a real context of receiving an ad. In addition, it does not highlight the impact of self-efficacy on the attitude towards an advertisement and persuasion. Finally, it is limited in its generalization. It is possible that the observed effects are reduced to the target respondents. Most respondents are young (20-29) and healthy. It would be interesting to use in a future study a sample of older and less healthy people. 
This study contributes to a better understanding of the impact of self-efficacy on the intention to stop smoking and the perception of ethical advertising. The contribution is also useful because it provides a framework and guidance for the development of public health communication campaigns using effectively and ethically fear appeals.

Bandura (1977) recommends verbal persuasion and vicarious learning to increase self-efficacy. Gallopel (2006) reports that studies of fear focused particularly on the apprehension of selfefficacy in terms of verbal persuasion. Providing information and instructions on "where to buy condoms, how to use ..." increases self-confidence and therefore self-efficacy. Practitioners are also required to act on self-efficacy through vicarious learning dimension that has never been tested by the researchers who worked on fear and social persuasion (Gallopel, 2006). Similarly, it would be interesting to see whether the testimony of former smokers, alcoholics ..., opinion leaders (actors, singers ...) enhance self-efficacy perceived by young people because they are very susceptible to peer pressure (Pechmann and Knight, 2002). It would be interesting to study the effectiveness of this strategy in relationship to the informative way. Finally, future research should examine how these links work in other contexts such as environmental protection, the struggle against road accidents, and alcoholism or as part of commercial communications. Studies to extend this research could continue to examine the effect of individual values on the perception of ethical advertising.

\section{References}

Aaker, D. A. \& Douglas, M. S. (1990). "Measuring Audience Perceptions of Commercials and Relating Them To Ad Impact," Journal of Advertising Research, 30 (4), 7-17.

Ajzen, I. (1985). From Intentions to Actions: A Theory of Planned Behavior. In J. Kuhl \& J. Beckman (Eds.), Action-control:
From cognition to behavior (pp. 11-39). Heidelberg: Springer.

Ajzen, I. (1991). "The Theory of Planned Behavior," Organizational Behavior and Human Decision Processes, 50, 179-211.

Andersen, R. B. (2000). "Vicarious and Persuasive Influences on Efficacy Expectations and Intentions to Perform Breast Self-examination," Public Relations Review, 26 (1), 97-114.

Arthur, D. \& Quester, P. (2003). "The Ethicality of Using Fear for Social Advertising," Australasian Marketing Journal, 11 (1), 12-27.

Arthur, D. \& Quester, P. (2004). "Who's Afraid of that Ad? Applying Segmentation to the PMM," Psychology and Marketing, 21 (9), 671-696.

Bandura, A. (1994). 'Self-efficacy in V.S. Ramachaudran,' (Ed.), Encyclopedia of Human Behavior (Vol.4, pp: 77-81). New York: Academic Press. (Reprinted in $\mathrm{H}$. Friedman [Ed.], Encyclopedia of mental health. San Diego: Academic Press, 1998).

Bandura, A. (2003). 'Le Sentiment D'efficacité Personnelle,' Paris : De Boeck.

Bécheur, I., Dib, H., Merunka, D. \& ValetteFlorence, P. (2007). "Emotions of Fear, Guilt or Shame in Anti-Alcohol Messages: Measuring Direct Effects on Persuasion and the Moderating Role of Sensation Seeking," The European Conference of the Association for Consumer Research, Milan, Italy.

Dao, T. (2004). 'Importation du Sentiment d'efficacité Personnelle en Comportement du Consommateur,' in Actes du XXe congrès AFM, St Malo, 1-27.

Duke, C. R., Pickett, G. M., Carlson, L. \& Grove, S. J. (1993). "A Method for Evaluating the Ethics of Fear Appeals," Journal of Public Policy and Marketing, 12(1), 120-129.

Eckart, J. (2011). 'Mind Control Tactic Fear Appeal,' NLP \& Hypnosis, April 5, 1. 
Etter, J. F., Bergman, M. M., Humair, J. P. \& Perneger, T. V. (2000). "Development and Validation of a Scale Measuring Selfefficacy of Current and Former Smokers," Addiction, 95 (6), 901-913.

Evans, R. I., Rozelle, T. M., Lasater, T. M. \& Dembroski, B. P. (1970). "Fear Arousal, Persuasion and Actual Versus Implied Behavior Change: New Perspectives Utilizing a Real-life Dental Hygiene Program," Journal of Personality and Social Psychology, 16, 220-227.

Fishbein, M. (1980). "A Theory of Reasoned Action: Some Applications and Implications," Nebraska Symposium on Motivation, 27, 65-116.

Fishbein, M. \& Ajzen, A. (1975). "Belief, Attitude, Intention and Behavior: An Introduction to Theory and Research," Reading, MA, Addison-Wesley.

Gallopel, K. (2006). "Peur et Persuasion Sociale : Etat de l'art, Limites et Voies de Recherche," Recherches et Application en Marketing, 21(4), 41-60.

Gallopel, k. \& Petr, C. (2000). 'Utilisation de la Peur dans les Campagnes de Prévention des Comportements Tabagiques : Résultats et Discussions autour des Jeunes Français,' Actes du Colloque "les Tendances $d u$ Marketing en Europe ", Universita Ca'Foscari-Venise.

Garlin, F. \& McGuiggan, R. (2002). "Exploring the Sources of Self-Efficacy in Consumer Behavior," in Asia Pacific Advances in Consumer Research, 5, eds. Ramizwick and Tu Ping, Valdosta, GA : Association for Consumer Research, 80-86.

Girandola, F. (2000). "Peur et Persuasion: Présentations des Recherches (1953-1998) et d'une Nouvelle Lecture," L'année Psychologique, PUF, 333-376.

Girandola, F. (2004). 'Menacer pour Convaincre?,' Cerveau et Psycho, $n^{\circ} 5$, Pour la Science.

Hale, J. L. \& Dillard, J. P. (1995). "Fear Appeals in Health Promotion Campaigns:
Too Much, too Little, or Just Right?," In Designing Health Messages: Approaches From Communication Theory And Public Health Practice, Maibach E and Parrott RL (Eds), Sage Publications, Inc, Thousands Oaks, CA, 65-80.

Hastings, G., Stead, M. \& Webb, J. (2004). "Fear Appeals in Social Marketing: Strategic and Ethical Reasons for Concern," Psychology and Marketing, 21(11), 961986.

Holbrook, M. (1994). "Ethics in Consumer Research: An Overview and Prospectus," Advances in Consumer Research, 3 (21), 566-571.

Hunt, D. M. \& Shehryar, O. (2002). 'The Nature of Fear Arousal and Segmentation of Target Audience in Fear Appeal Advertising: A Terror Management Perspective,' American Marketing Association, 13, p51.

Hyman, M. R. \& Tansey, R. (1990). "The Ethics of Psychoactive Ads," Journal of Business Ethics, 9(2), 105-114.

Kaper, J., Wagena E. J., Willemsen, M. C. \& Schayck, C. P. (2005). "Reimbursement for Smoking Cessation Treatment May Double the Abstinence Rate: Results of a Randomized Trial," Society for the Study of Addiction. Department of General Practise Care and Public Health Research Institute.

Kapferer, J.- N. (1990). Les Chemins de la Persuasion. Le Mode D'Influence des Media et de la Publicité sur les Comportements, Dunod.

Keller, P. A. \& Block, L. G. (1996). "Increasing the Persuasiveness of Fear Appeals: the Effect of Arousal and Elaboration," Journal of Consumer Research, 22 (4), 449-459.

LaTour, M. S. \& Henthorne, T. L. (1994). "Ethical Judgement of Sexual Appeals in Print Advertising," Journal of Advertising, 26 (3), 81-90.

LaTour, M. S. \& Pitts, R. E. (1989). "Using Fear Appeals in Advertising for AIDS Prevention in the College-Age Population," 
Journal of Health Care Marketing, 9(3), 514.

LaTour, M. S. \& Rotfeld, H. J. (1997). "There are Threats and (Maybe) Fear-caused Arousal: Theory and Confusions of Appeals to Fear and Fear Arousal Itself," Journal of Advertising, 26 (3), 45 - 59.

LaTour, M. S. \& Zahra, S. A. (1989). "Fear Appeals as Advertising Strategy: Should They be Used?," Journal of Consumer Marketing, 6 (3), 61-70.

LaTour, M. S., Snipes, R. L. \& Bliss, S. J. (1996). "Don't Be Afraid to Use Fear Appeals: An Experimental Study," Journal of Advertising Research, 36(2), 59-68.

Leventhal, H., Watts, J. C. \& Pagano, F. (1967). " Effects of Fear Arousing Communications on How to Cope with Danger," Journal of Personality and Social Psychology, 6, 313-321.

Métayer, M. (1997). 'La Philosophie éthique : Enjeux et Débats Actuels,' Editions du Renouveau Pédagogique INC.

Mostafa, M. M. (2011). "An Investigation of Egyptian Consumers' Attitudes toward Ethical Issues in Advertising," Journal of Promotion Management, 17(1), 42-49.

Palmer-Mehta, V. (2009). "Motivational Appeals and Ethics," Communication Teacher, 23(1), 41-47.

Pechmann, C. \& Knight, S. J. (2002). "An Experimental Investigation of the Joint Effects of Advertising and Peers on Adolescents' Beliefs and Intentions about Cigarette Consumption," Journal of Consumer Research, 29 (1), 5-19.

Pechmann, C., Zhao, G., Goldberg, M. E. \& Reibling, E. T. (2003). "What to Convey in Antismoking Advertisements for Adolescents: The use of Protection Motivation Theory to identify Effective Message Themes," Journal of Marketing, 67, 1-18.

Reindenbach, R. E. \& Robin, D. P. (1988). "Some Initial Steps Toward Improving the
Measurement of Ethical Evaluations of Marketing Activities," Journal of Business Ethics, 7, 870-878.

Reindenbach, R. E. \& Robin, D. P. (1990). "Toward the Development of Multidimensional Scale of Improving Evaluations of Business Ethics," Journal of Business Ethics, 9 (8), 639-653.

Rogers, R. W. (1975). "A Protection Motivation Theory of Fear appeals and Attitude Change," The Journal of Psychology, 91, 93-114.

Rogers, R. W. (1983). 'Cognitive and Physiological Processes in Fear Appeal and Attitude Change: A Revisited Theory of Protection Motivation,' in Social Psychophysisiology, J Cacioppo and R Petty, Eds, New York: Guilfort press, 153-176.

Rotfeld, H. J. (1988). "Fear Appeals and Persuasion: Assumptions and Errors in Advertising Research," Current Issues and Research in Advertising, 11(1), 21-40.

Simpson, P. M. (1992). 'An Examination of Ethical Judgments and Selected Advertising Response Variables: A Structural Modeling Approach,' 199 pages.

Simpson, P. M., Brown, G. \& Widing, R. E. (1998). "The Association of Ethical Judgment of Advertising and Selected Advertising Effectiveness Response Variables," Journal of Business Ethics, 17(2), 125-137.

Snipes, R. L., La Tour M. S. \& Bliss, S. J. (1999). "A Model of the Effects of Selfefficacy on the Perceived Ethicality and Performance of Fear Appeals in Advertising," Journal of Business Ethics, 19 (3), 273-285.

Sutton, S. R. \& Eiser, J. R. (1984). "The Effect of Fear -arousing Communications on Cigarette Smoking: An Expectancy-Value Approach," Journal of Behavioural Medicine, 7, 13-33.

Tanner, J. F., Day, E. \& Crask, M. R. (1989). "Protection Motivation Theory: An Extension of Fear Appeals Theory in 
Communication," Journal of Business Research, 19(3), 267-276.

Tanner, J. F., Hunt, J. B. \& Eppright, D. R. (1991). "The Protection Motivation Model: A Normative Model of Fear Appeals," Journal of Marketing, 55 (3), 36-45.

Thiétart, R. A. \& coll. (1999). 'Méthodes de Recherche En Management,' Dunod.

Thompson, L. E., Barnett, J. R. \& Pearce, J. R. (2009). "Scared Straight? Fear-Appeal AntiSmoking Campaigns, Risk, Self-Efficacy and Addiction," Health, Risk \& Society, 11(2), 181-196.

Thorson \& Friestad (1985). 'Advertising: Sold on Emotion,' Psychology Today, 19 (3), 9.

Trefois, P. (2003). Peur et Prévention Bruxelles Santé, 31, 1- 49.

Treise, D., Weigold, M. F., Conna, J. \& Garrison, H. (1994). "Ethics in Advertising: Ideological Correlates of Consumer Perceptions," Journal of Advertising, 23(3), 60-69.

Warshaw, P. R. (1980). "A New Model for Predicting Behavioral Intentions: An Alternative to Fishbein," Journal of Marketing Research, 17 (2), 153-172.

Williams, K. C. (2012). "Improving Fear Appeal Ethics," Journal of Academic and Business Ethics, 5, March, 46-69.

Witte, K. (1992). "Putting the Fear Back into Fear Appeals: The Extended Parallel Process Model," Communication Monographs, 59 (4), 329-349.

Witte, K. \& Allen, M. (2000). "A MetaAnalysis of Fear Appeals: Implications for Effective Public Health Campaigns," Health Education and Behavior, 27(5), 591-615. 